\title{
MKP1-dependent PTH modulation of bone matrix mineralization in female mice is osteoblast maturation stage specific and involves P-ERK and P-p38 MAPKs
}

\author{
Chandrika D Mahalingam', Bharat Reddy Sampathi', Sonali Sharma', Tanuka Datta', \\ Varsha Das', Abdul B Abou-Samra' and Nabanita S Datta ${ }^{1,2,3}$ \\ ${ }^{1}$ Division of Endocrinology, Department of Internal Medicine, Wayne State University School of Medicine, \\ 1107 Elliman Clinical Research Building, 421 East Canfield Avenue, Detroit, Michigan 48201, USA \\ ${ }^{2}$ Barbara Ann Karmanos Cancer Institute and ${ }^{3}$ Cardiovascular Research Institute, Wayne State University School of \\ Medicine, Detroit, Michigan 48201, USA
}

Correspondence should be addressed to N S Datta

Email

ndatta@med.wayne.edu

\begin{abstract}
Limited information is available on the role of MAPK phosphatase 1 (MKP1) signaling in osteoblasts. We have recently reported distinct roles for MKP1 during osteoblast proliferation, differentiation, and skeletal responsiveness to parathyroid hormone (PTH). As MKP1 regulates the phosphorylation status of MAPKs, we investigated the involvement of P-ERK and P-p38 MAPKs in MKP1 knockout (KO) early and mature osteoblasts with respect to mineralization and PTH response. Calvarial osteoblasts from 9-14-week-old WT and MKP1 KO male and female mice were examined. Western blot analysis revealed downregulation and sustained expressions of P-ERK and P-p38 with PTH treatment in differentiated osteoblasts derived from $\mathrm{KO}$ males and females respectively. Exposure of early osteoblasts to p38 inhibitor, SB203580 (S), markedly inhibited mineralization in WT and KO osteoblasts from both genders as determined by von Kossa assay. In osteoblasts from males, ERK inhibitor U0126 (U), not p38 inhibitor (S), prevented the inhibitory effects of PTH on mineralization in early or mature osteoblasts. In osteoblasts from KO females, PTH sustained mineralization in early osteoblasts and decreased mineralization in mature cells. This effect of PTH was attenuated by $S$ in early osteoblasts and by $U$ in mature $\mathrm{KO}$ cells. Changes in matrix Gla protein expression with PTH in KO osteoblasts did not correlate with mineralization, indicative of MKP1-dependent additional mechanisms essential for PTH action on osteoblast mineralization. We conclude that PTH regulation of osteoblast mineralization in female mice is maturation stage specific and involves MKP1 modulation of P-ERK and P-p38 MAPKs.
\end{abstract}
Key Words
- osteoblast
- mineralization
- MKP1
- MAPK
- PTH

Journal of Endocrinology (2013) 216, 315-329 http://joe.endocrinology-journals.org DOI: 10.1530/JOE-12-0372
() 2013 Society for Endocrinology Printed in Great Britain
Published by Bioscientifica Ltd 


\section{Introduction}

Bone homeostasis is maintained by a balance between bone-building osteoblasts and bone-resorbing osteoclasts, a process known as bone remodeling (Feng \& McDonald 2011, Kular et al. 2012). Age-related bone loss is associated with changes in bone remodeling characterized by decreased bone formation relative to bone resorption, resulting in bone fragility, increased risk of fractures, and osteoporosis (Khosla \& Riggs 2005, Raisz 2005, Feng \& McDonald 2011). Bisphosphonates are widely prescribed anti-resorptive agents that inhibit osteoclast attachment to bone matrix and enhance osteoclast apoptosis (Dominguez et al. 2011). However, there are risks associated with bisphosphonate therapy (Khosla et al. 2012). A new therapeutic approach for treating osteoporosis includes anabolic agents that promote osteoblastic differentiation leading to increased bone formation. Daily injection of parathyroid hormone (PTH), PTH (1-34), has been shown to be anabolic (Greenfield 2012) and increases bone mass through the stimulation of trabecular and cortical bone formation and decreases fracture incidences in severe cases of osteoporosis (for review, see Datta (2011)). However, the therapeutic use of PTH is limited by the principal side effects of hypercalcemia (Miller et al. 2007) and possible bone cancer concerns (Cappuzzo \& Delafuente 2004).

As osteoporosis is a disorder of remodeling in which bone resorption outstrips formation, any insights into pathways that control bone formation and PTH molecular action have potential therapeutic implications. PTH plays important roles at multiple stages during bone formation having both anabolic and catabolic effects in bone (Qin et al. 2004, Silva et al. 2011). The anabolic actions of PTH involve direct effects on osteoblasts such as cell survival (Manolagas 2000), osteoblast proliferation, differentiation (Nishida et al. 1994, Datta et al. 2005, 2007, 2010a), and mature osteoblast function (Qin et al. 2004). The indirect effects include activation of skeletal growth factors (Lombardi et al. 2010, Bikle \& Wang 2012, Fei \& Hurley 2012) and inhibition of growth factor antagonists, such as sclerostin (Yu et al. 2011). The mediators of PTH intracellular signaling pathways are not well defined relative to specific actions. PTH regulates bone remodeling by activating distinct signaling pathways including MAPK pathways in osteoblasts via PTH receptor-1 (PTH1R; for review, see Datta \& Abou-Samra (2009)). MAPK cascades are conserved signal transduction pathways that are regulated in response to diverse stimuli and mediate physiological responses including cell proliferation, differentiation, and transformation (Dong et al. 2002, Wada \& Penninger 2004). MAPK signaling is both diverse and complex and dependent on a balance between activation by kinases and inactivation by MAPK phosphatases (MKP; Owens \& Keyse 2007). It has been suggested that signaling through multiple MAPK pathways may be integrated at the level of regulation by MKPs (Owens \& Keyse 2007). We have previously demonstrated that PTH and PTH-related peptide regulate osteoblast cell cycle by regulating the expressions of cyclin D1, CDK1, and JunB and the activity of ERK-MAPK (Datta et al. 2005, 2007, 2010b, 2012). Recent observations by us and others implicating MKP1 in maintaining bone homeostasis and in PTH regulation brings the field one step closer to finding another possible treatment (Carlson et al. 2009, Datta et al. 2010a, Mahalingam et al. 2011).

Bone mineralization is an essential process that improves hardness and strength of the skeleton of the vertebrates. Osteoblasts pass through a series of stages before reaching maturity and bone matrix mineralization. Differentiation of osteoblasts in vitro and in vivo can be characterized in three stages: i) cell proliferation, ii) matrix maturation, and iii) matrix mineralization (Stein \& Lian 1993). The mineralization process of osteoblasts in in vitro culture has been used as a model for testing PTH regulation on bone cell differentiation and bone formation (Kostenuik et al. 1999). In this paper, we explored the involvement of MKP1 in ERKand p38 MAPK-mediated osteoblast mineralization and PTH action by studying primary osteoblasts derived from MKP1 knockout (KO) mice. The role of the MKP1-MAPK pathway in osteoblast proliferation and differentiation may depend on the maturation stage in which PTH signaling is studied (Datta et al. 2005, 2007). It is therefore important to consider the precise stage of osteoblast maturation in which MKP1 signaling is presented. Here, we show that osteoblast mineralization requires MKP1 and P-p38-MAPK depending on the maturation stages of the osteoblasts. Our data support the notion that MKP1 in osteoblasts from females plays a key role in mineral homeostasis predominantly mediated by p38 MAPK. PTH signal transduction differs from early to late osteoblasts, targeting both P-ERK and P-p38-MAPK pathways. Furthermore, these data suggest a disparate PTH regulation of osteoblast mineralization in male and female MKP1 KO mice.

\section{Materials and methods}

\section{Animals}

MKP1 KO mice were obtained through a Material Transfer Agreement from Bristol-Myers Squibb as previously described (Dorfman et al. 1996, Zhao et al. 2005,

Published by Bioscientifica Ltd 
Mahalingam et al. 2011). These mice, containing a disruption within exon 2 of MKP1, were bred in-house either intercrossing heterozygous or homozygous $\mathrm{KO}$ breeders to yield both WT and KO mice. The experiments in this study were performed with 9-14-week-old WT and KO male and female mice fed with rodent chow (Lab diet, Brentwood, MD, USA). For genotyping, real-time PCR analysis was performed by Transnetyx (Cordova, TN, USA) (Mahalingam et al. 2011). All animals were maintained in facilities operated by Wayne State University, and all animal experimental procedures were approved by the Institutional Animal Care and Use Committee for the Use and Care of Animals (IACUC).

\section{Antibodies and reagents}

Antibodies to phospho-ERK, total ERK, and phospho-p38 were obtained from Cell Signaling (Beverly, MA, USA). Cyclin D1 was from Santa Cruz Biotechnology and glyceraldehyde 3-phospho-dehydrogenase (GAPDH) was from Sigma. Secondary antibody HRP conjugates to rabbit or mouse immunoglobulins were obtained from GE Healthcare Life Sciences (Pittsburg, PA, USA). Tissue culture medium and fetal bovine serum (FBS) were from Invitrogen. Human PTH (PTH1-34) was purchased from Bachem (Torrance, CA, USA). U0126, the MEK inhibitor, was from Promega and SB203580, the phospho-p38 inhibitor, was obtained from EMD Biosciences (Darmstadt, Germany). 3-(4,5-Dimethylthiazol-2yl)-2,5-diphenyl-2Htetrazolium bromide (MTT) was from Sigma-Aldrich.

\section{Primary osteoblast cell culture}

Primary osteoblasts were isolated from calvaria by serial digestion (Datta et al. 2005). Briefly, calvaria were dissected, isolated, and subjected to sequential digestions in collagenase A $(2 \mathrm{mg} / \mathrm{ml})$ and trypsin $(0.25 \%)$ for 20,40 , and $90 \mathrm{~min}$. Cells from the third digest were rinsed, counted, and plated in primary culture medium containing $\alpha \mathrm{MEM}$, $10 \% \mathrm{FBS}, 100 \mathrm{U} / \mathrm{ml}$ penicillin, and $1 \mu \mathrm{g} / \mathrm{ml}$ streptomycin.

\section{Cell proliferation}

Cell proliferation was determined by plating primary osteoblasts at first passage at a density of 10000 cells/well in 24-well plates. Media were changed every other day until cell enumeration. Cell-doubling was calculated either from hemocytometer counts using the trypan blue exclusion method (not shown) or by the MTT reduction to formazan in living cells as a measure of mitochondrial activity. PBS solution of MTT $(0.5 \mathrm{mg} / \mathrm{ml})$ was incubated with cells in 24-well plates for $4 \mathrm{~h}$. The resulting formazan crystals were dissolved by addition of $500 \mu \mathrm{l}$ isopropyl alcohol to each well and optical density read at a wavelength of $595 \mathrm{~nm}$.

\section{Osteoblast differentiation, SDS-PAGE, and western blot analysis}

Calvarial osteoblasts were differentiated for 7 days with ascorbic acid $(50 \mu \mathrm{g} / \mathrm{ml})$ and $\beta$-glycerophosphate $(10 \mathrm{mM})$ and induced with $100 \mathrm{nM}$ PTH for $10 \mathrm{~min}$ to $5 \mathrm{~h}$ for subsequent experiments. SDS-PAGE was performed in $10-12 \%$ polyacrylamide and western blot analysis was performed as described previously (Datta et al. 2005). Each lane was loaded with $40-80 \mu \mathrm{g}$ protein of cell lysates. Prestained molecular weight standards were run in parallel lanes. After electrophoresis, the proteins were transferred to a PVDF membrane (Bio-Rad Laboratories) in $25 \mathrm{mM}$ Tris-HCl, $192 \mathrm{mM}$ glycine, 20\% v/v methanol, and $0.01 \%$ SDS (pH 8.5) using a semi-dry transfer system (Hoeffer, Holliston, MA, USA). Residual protein binding sites on the membrane were blocked by TBST ( $20 \mathrm{mM}$ Tris$\mathrm{HCl}, \mathrm{pH} 7.6,137 \mathrm{mM} \mathrm{NaCl}$, and 0.5\% Tween 20) containing 5\% nonfat dry milk for $1 \mathrm{~h}$ at room temperature. The membranes were then incubated with the primary antiserum for either $1-2 \mathrm{~h}$ at room temperature or overnight at $4{ }^{\circ} \mathrm{C}$. After washing with TBST, a HRPconjugated secondary antibody was added for 20-60 min. The protein bands were visualized by autoradiography using an ECL detection system (Pierce, Rockford, IL, USA). The protein band intensities on the autoradiograms (all with exposures within the linear range of the film) were quantified using Scion software (Frederick, MD, USA).

\section{Osteoblast differentiation and PTH, U0126, and SB203580 administrations}

Freshly isolated calvarial osteoblasts were plated at a density of 200000 cells/well in six-well plates and allowed cell attachment onto culture dishes for 3 days. After removal of nonadherent cells, primary osteoblasts were subjected to differentiation, as earlier, in osteogenic medium containing ascorbic acid $(50 \mu \mathrm{g} / \mathrm{ml})$ and $\beta$-glycerophosphate $(10 \mathrm{mM})$. Two treatment plans were initiated as follows.

Plan 1 Adherent early osteoblasts were exposed to U0126 $(20 \mu \mathrm{M})$, or SB203580 $(20 \mu \mathrm{M})$, either alone or in the presence of PTH $(1-34)(100 \mathrm{nM})$ from day 3 until days 18-20 in differentiation medium. Media with the inhibitors and/or PTH were replaced every other day.

Published by Bioscientifica Ltc. 
Plan 2 - Adherent osteoblasts were exposed to differentiation medium without inhibitors or PTH for 7 days from days 3 to day 10. At day 10, differentiated osteoblasts were exposed to U0126 $(20 \mu \mathrm{M})$ or SB203580 $(20 \mu \mathrm{M})$, either alone or in the presence of PTH (1-34) (100 nM) until days 20-23 in differentiation medium as earlier. Media with the inhibitors and/or PTH were replaced every other day.

\section{Osteoblast mineralization}

The mineralization assays were performed using the von Kossa method as described previously (Mahalingam et al. 2011). At the end of the culture period, the cells were fixed with phosphate buffer formalin, 95\% EtOH, and stained with $\mathrm{AgNO}_{3}$ to detect phosphate deposits in bone nodules as described (Marsh et al. 1995). The calcium phosphate deposits were observed by the formation of opaque mineralized nodules. The numbers of nodules were counted and plotted as percent relative expression compared to untreated WT cells. Undifferentiated osteoblasts were used as a negative control.

\section{Analysis of mRNA by real-time PCR}

mRNA isolation of cells were performed with TRIZOL reagent (Invitrogen), and cDNAs were prepared using the TaqMan Reverse Transcription assay system (Applied Biosystems) as described (Mahalingam et al. 2011). Realtime PCR was performed using StepOne Plus real-time PCR system (Applied Biosystems) with FAM-labeled primer assay systems (matrix Gla protein, MGP \#Mm00485009, GAPDH \# 99999915) from Applied Biosystems. GAPDH was used as an internal control.

\section{Statistical analysis}

All values were expressed as mean \pm s.E.M. Comparisons between groups were made by either unpaired two-tailed Student's $t$-test or ANOVA with the Instat Biostatistics program (GraphPad Software, San Diego, CA, USA) to determine significance between groups. $P$ values $<0.05$ were considered statistically significant.

\section{Results}

\section{Increased proliferation of calvarial osteoblasts derived from MKP1 KO mice}

To determine the role of MKP1 on the growth of primary calvarial osteoblasts, cells were derived from 9-10-week-old WT and MKP1 KO male and female mice.
Cell proliferation was examined by the MTT assay. The MTT reduction activity was increased ( $\sim 1.5$ - to 2 -fold) in KO cells from both sexes compared with respective WT controls, suggesting increased proliferation in KO osteoblasts (Fig. 1A and B). Proliferation of osteoblasts derived from male mice linearly increased during the first 3 days and then plateaued between days 4 and 10. The KO osteoblasts reached a significantly higher plateau ( 1.2- to 1.3 -fold) at days 4 and 5 compared with WT cells (Fig. 1A). By contrast, proliferation of cells derived from $\mathrm{KO}$ female mice increased in a linear fashion up to day 10 (Fig. 1B). The KO osteoblasts had a significantly higher ( 1.2- to 1.8-fold) MTT reduction activity between days 2 and 10 compared with WT controls (Fig. 1B). Similar to osteoblasts from WT and KO males, changes in the number of osteoblasts from WT females beyond
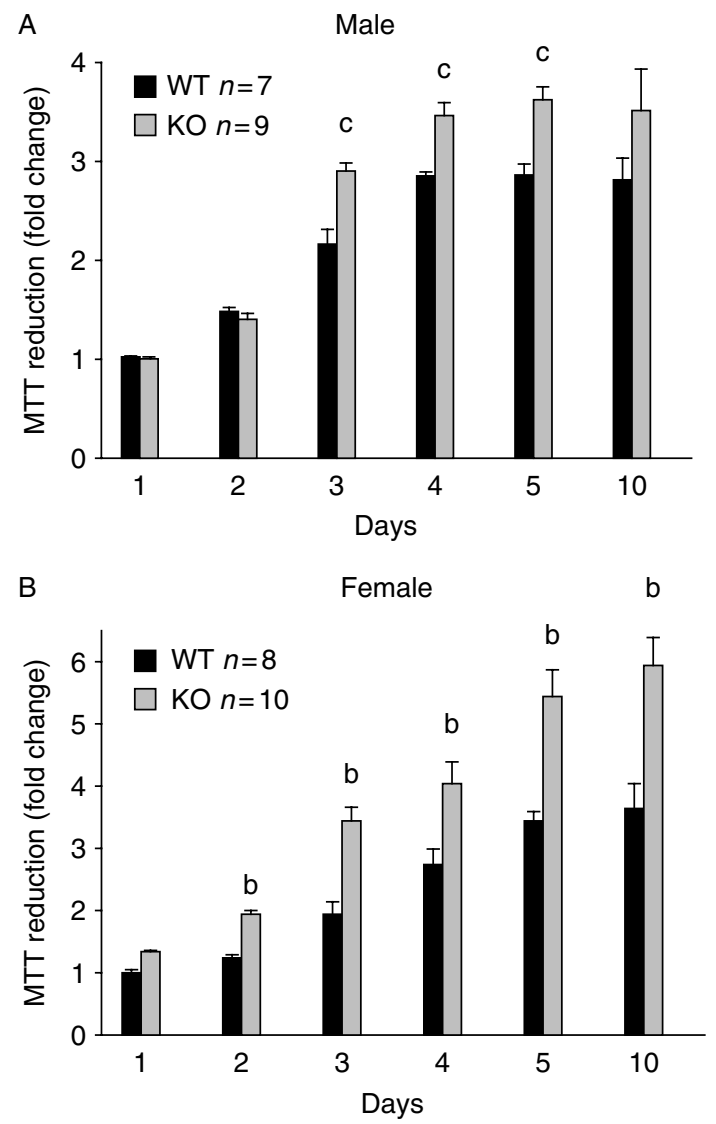

Figure 1

Analysis of MKP1 KO osteoblast proliferation in vitro. Calvarial osteoblasts were derived from 9-10-week-old (A) male and (B) female WT and MKP1 $\mathrm{KO}$ mice. Cell proliferation was assayed by MTT reduction activity as described in Materials and methods section. Data from three to four independent experiments are plotted. Values are mean \pm s.E.M. $(n=2-3$ for male and female WT and KO mice in each independent experiment), ${ }^{\mathrm{b}} P<0.02 ;{ }^{\mathrm{c}} P<0.05$.

Published by Bioscientifica Ltd. 
day 4 were not statistically significant. These results are consistent with our recent finding that loss of MKP1 delays or attenuates osteoblast differentiation in terms of activity and expressions of alkaline phosphatase (ALKP), OCN, ON, and Runx2 (Mahalingam et al. 2011) when compared with osteoblasts from WT females. We have also reported that PTH induces P-ERK and cyclin D1 in proliferating osteoblastic cells (Datta et al. 2007). We hypothesized that increased P-ERK upregulates cyclin D1 and stimulates osteoblast proliferation. As expected, in this study, the degree of proliferation in the MKP1 KO osteoblasts (where ERK remains phosphorylated and continued to be active) was not diminished following PTH administration (data not shown).

\section{Effect of MKP1 deletion on cyclin D1, MAPK expression, and PTH regulation}

Our previous studies reported that PTH1R activation downregulates P-ERK1/2 and cyclin D1 in differentiated MC3T3E1 osteoblastic cells (Chen et al. 2004, Datta et al. 2005), and this effect was attenuated in the absence of MKP1 in primary osteoblasts derived from female mice (Mahalingam et al. 2011). In this study, we examined the effects of PTH on Pp38, P-ERK, and cyclin D1 in 7-day differentiated MKP1 KO primary osteoblasts derived from both male and female mice. In osteoblasts derived from male mice, PTH decreased ( 40-60\%) P-ERK and P-p38 expression similarly in both WT and KO osteoblasts (Fig. 2A). On the other hand, in osteoblasts derived from female mice, the effects of PTH on P-ERK and P-p38 expression were attenuated in MKP1 KO osteoblasts when compared with WT cells (Fig. 2B), similar to our previous report (Mahalingam et al. 2011). PTH decreased (70-80\%) cyclin D1 protein expression in osteoblasts derived from both WT and MKP1 KO male mice (Fig. 2A). By contrast, the effect of PTH on cyclin D1 protein expression was attenuated in cells derived from female KO animals when compared with WT controls (Fig. 2B), similar to our previous observation (Mahalingam et al. 2011). These studies reveal a distinct molecular role for MKP1 in PTH signaling in differentiated osteoblasts derived from male and female mice.

\section{Disparate roles for MKP1 in PTH-regulated bone matrix mineralization of osteoblast cultures derived from male and female mice}

Continuous PTH administration inhibits osteoblast mineralization in vitro (Gopalakrishnan et al. 2005) and regulates matrix Gla protein (MGP), an inhibitor of
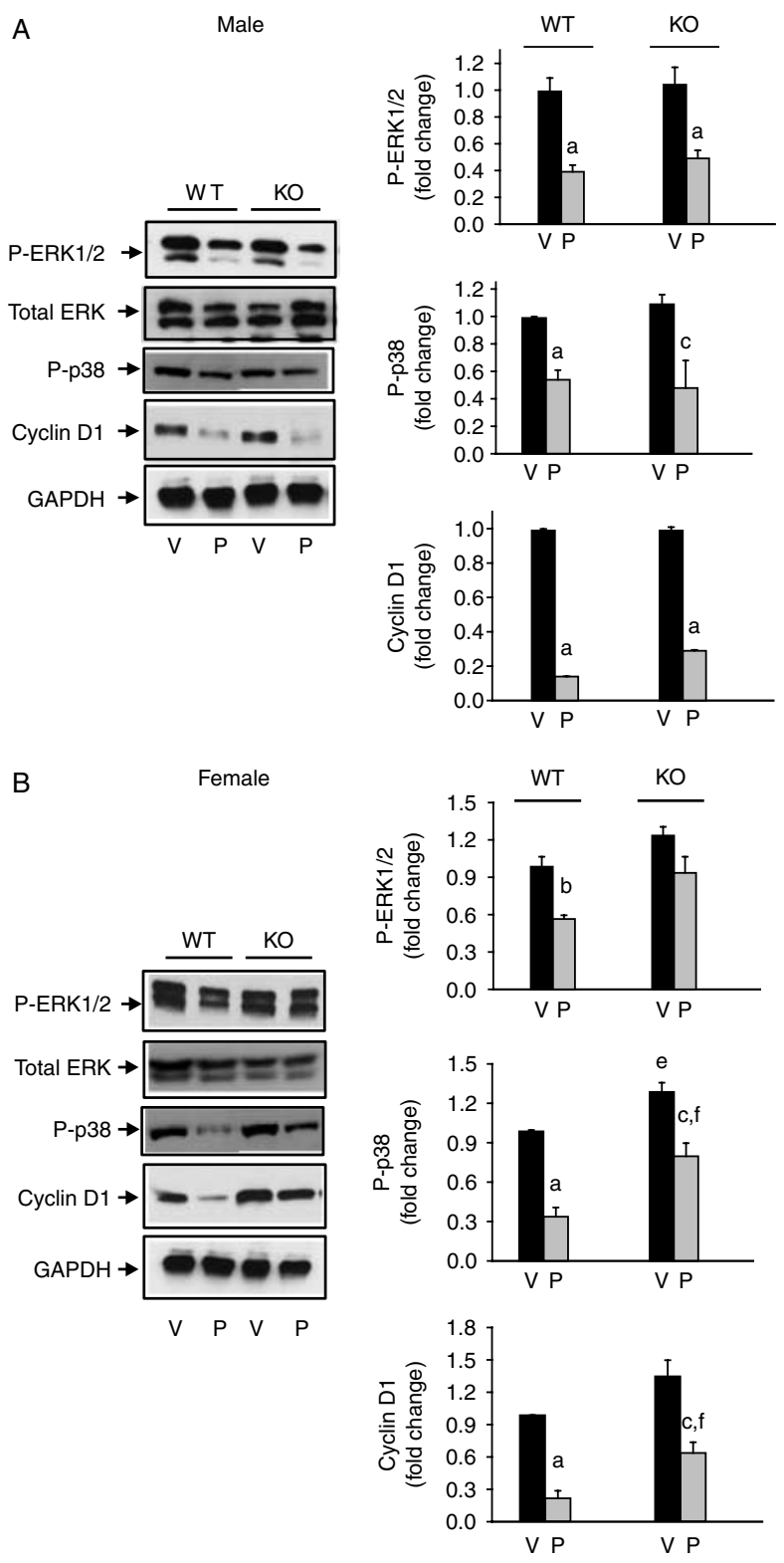

Figure 2

Effect of PTH on P-ERK, P-p38 MAPK, and cyclin D1 in MKP1 KO osteoblasts. Seven-day differentiated calvarial osteoblasts from 12-14-week-old WT and $\mathrm{KO}(\mathrm{A})$ male and (B) female mice were treated with $100 \mathrm{nM}$ PTH (P) or vehicle (V) for either $10 \mathrm{~min}$ (P-ERK), 1-2 h (P-p38), or $5 \mathrm{~h}$ (cyclin D1). Total cellular protein was harvested. Western blot analyses were performed for P-ERK1/2, total ERK, P-p38, cyclin D1, and GAPDH. Total ERK and GAPDH were used as loading controls. Densitometric values were normalized and plotted as fold changes with respect to WT-V-treated cells as described in Materials and methods section. Representative data from at least three to four independent experiments are shown. Data are expressed as mean \pm s.E.M. from three to four independent experiments $(n=2-3$ for male and female WT and KO mice in each experiment). ${ }^{\mathrm{a}} P<0.001$ vs $V_{;}{ }^{\mathrm{b}} P<0.02$ vs V; ${ }^{\mathrm{C}} \boldsymbol{P}<0.05$ vs V; ${ }^{\mathrm{e}} \boldsymbol{P}<0.05$ vs WT-V; ${ }^{\mathrm{f}} \boldsymbol{P}<0.05$ vs WT-P. http://joe.endocrinology-journals.org DOI: 10.1530/JOE-12-0372
(C) 2013 Society for Endocrinology Printed in Great Britain 
A

Male
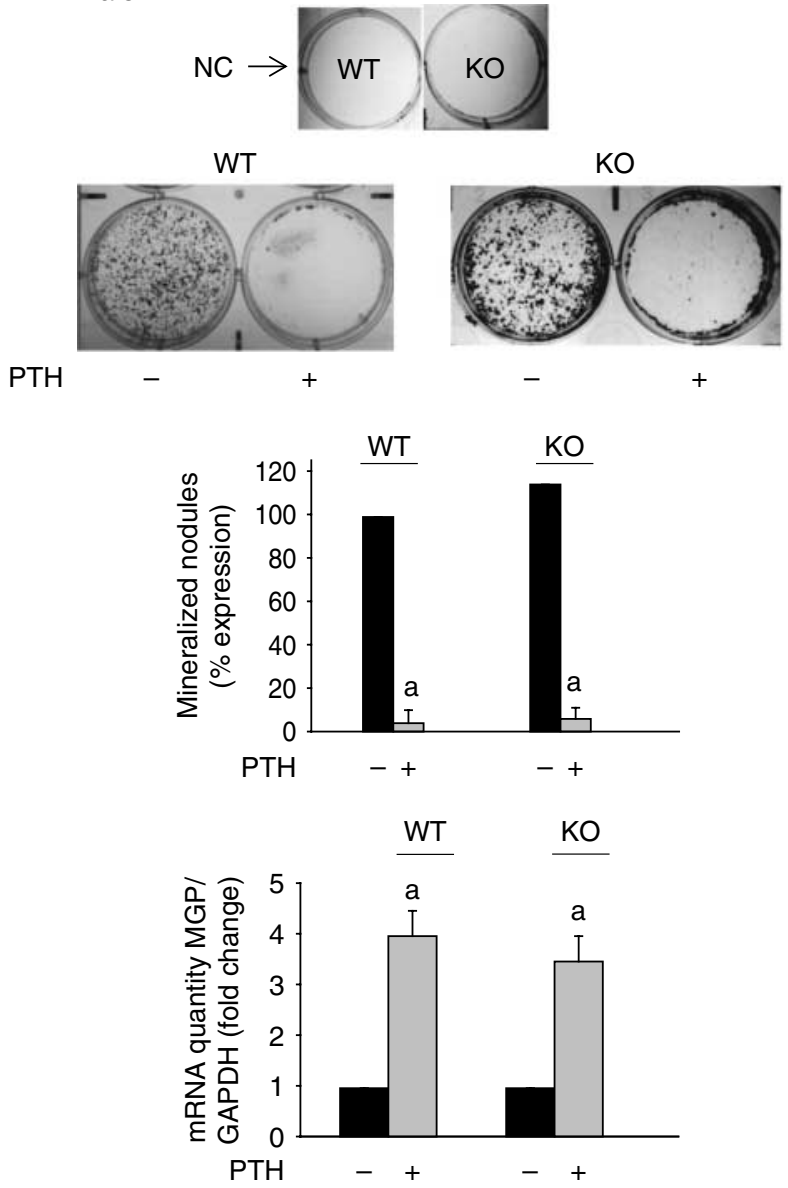

Figure 3

Effect of PTH on MKP1 KO osteoblast mineralization and MGP expression: Osteoblasts were isolated from calvaria of 12-14-week-old WT and MKP1 $\mathrm{KO}(\mathrm{A})$ male and (B) female mice. After cell attachment, differentiation of the cells was initiated with ascorbic acid and $\beta$-glycerophosphate with or without 100 nM PTH for 15-21 days. Mineralized nodule formation was examined by von Kossa staining as described in Materials and methods section. Representative wells from six to eight individual experiments with similar results for nodule formation are shown. The number of nodules was counted and plotted as \% expression of nodules with respect to PTHuntreated WT cells. Total RNA was isolated from triplicate independent

mineralization (Gopalakrishnan et al. 2001). To evaluate the effects of MKP1 deletion on in vitro osteoblastogenesis and cell maturation, calvarial osteoblasts from 12-14week-old male and female WT and KO mice following isolation and cell attachment were differentiated in the presence or absence of PTH and mineralized nodule formation was assessed by von Kossa staining. In osteoblasts derived from male mice, PTH dramatically decreased mineralization and increased $M g p$ mRNA to similar degrees (90-95\%) in WT and KO cells (Fig. 3A). By contrast, osteoblasts derived from female mice PTH inhibited mineralization by only $15-20 \%$ in MKP1 KO cells
B Female
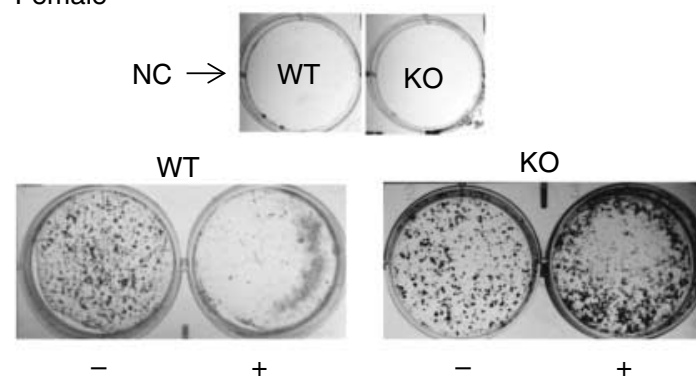

PTH
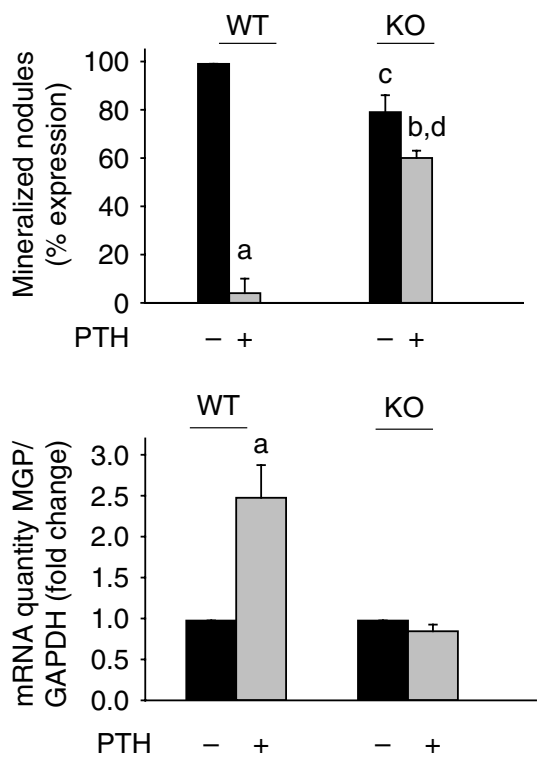

cultures at day 15 with and without PTH treatment, and Mgp mRNA expression was quantified in (A) male and (B) female WT and KO osteoblasts by real-time PCR analysis as described in Materials and methods section. Results are graphically represented after normalization with GAPDH as fold change with respect to PTH-untreated differentiated cells from WT cultures. Values are expressed as mean \pm S.E.M. from six to eight independent experiments ( $n=2-3$ for male and female WT and KO mice in each experiment). ${ }^{\mathrm{a}} P<0.001$ vs untreated cells; ${ }^{\mathrm{b}} P<0.05$ vs untreated cells; ${ }^{c} P<0.05$ vs untreated WT control cells; ${ }^{d} P<0.001$ vs PTH treated WT control cells. NC, negative control, undifferentiated osteoblasts.

and had no effect on Mgp mRNA expression (Fig. 3B; Mahalingam et al. 2011). The effects of PTH on WT osteoblasts from females were similar to those derived from males (90-95\% inhibition of mineralization and several fold stimulation of Mgp mRNA expression, Fig. 3A and B).

Roles of MKP1, P-p38, and P-ERK signaling in PTH effect on mineralization in early vs mature osteoblasts

Our previous studies suggested that MKP1 regulates osteoblast proliferation/differentiation and mineralization (Datta et al. 2010a, Mahalingam et al. 2011).

Published by Bioscientifica Ltd. 
A

Plan1

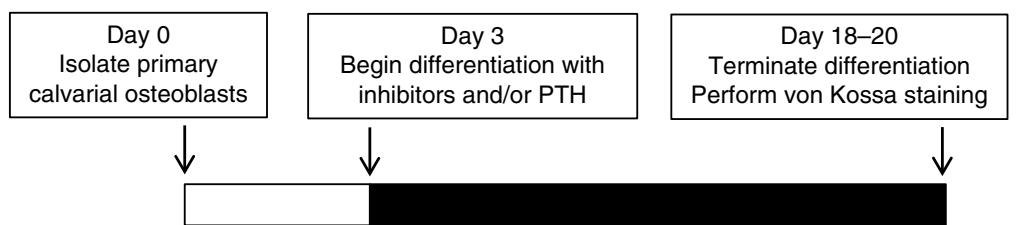

B

Plan 2

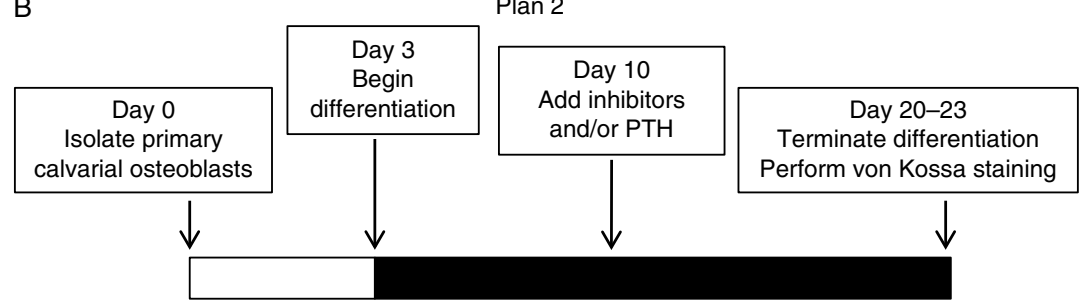

Figure 4

Treatment plans for primary osteoblast differentiation. Freshly isolated calvarial osteoblasts from male and female WT and KO mice were plated for 3 days for cell attachment. After removing the nonadherent cells, these were differentiated in osteogenic media and subjected to two different treatment plans as described in Materials and methods section. (A) In treatment plan 1, adherent early osteoblasts were exposed to $20 \mu \mathrm{M}$ U0126, ERK-MAPK inhibitor or $20 \mu \mathrm{M}$ SB203580, p38 MAPK

As MKP1 regulates P-ERK and P-p38, we examined the involvement of ERK and p38 MAPKs in PTH-MKP1 signaling. WT and KO osteoblasts were treated with PTH in the presence or absence of pharmacological inhibitors during differentiation. In this study, the specific inhibitors were titrated in WT osteoblasts for maximal suppression of P-ERK and P-p38 (not shown), and for least nonspecific toxic effects (Xiao et al. 2002). We designed our experiments with two different treatment plans (Fig. 4). In treatment plan 1, following primary calvarial osteoblast isolation and cell attachment onto culture dishes, differentiation was initiated at day 3 and specific inhibitors for P-ERK and P-p38 with or without PTH were added until the end of experiment (Fig. 4A). In treatment plan 2, the cells were first allowed to differentiate from days 3 to 10 and then the respective inhibitors were added, with or without PTH, from day 10 until the end of experiment (Fig. 4B). Thus, treatment plan 1 examined the involvement of P-ERK and P-p38 in PTH-MKP1 signaling in early osteoblasts whereas plan 2 examined their effects on mature osteoblasts.

Figure 5 shows the results in osteoblasts isolated from male WT (Fig. 5A) and KO (Fig. 5B) mice. The MEK/ERK inhibitor, U0126 (U), showed an increased tendency of mineralization compared with untreated differentiated inhibitor in the presence or absence of $100 \mathrm{nM}$ PTH from day 3 until days 18-20 in differentiation media, and processed. Media with the inhibitors and/or PTH were replaced every other day. (B) In treatment plan 2, adherent cells were first allowed to differentiate for 7 days without inhibitors or PTH from day 3 to day 10. At day 10, the cells were exposed to inhibitors in the presence or absence of PTH, as in treatment plan 1, until days $18-20$ in differentiation media and processed.

cells ( $\mathrm{AB}$ vs $\mathrm{ABU}$ ), either in treatment plan 1 or in treatment plan 2 similarly in WT (Fig. 5A) and $\mathrm{KO}$ (Fig. 5B) osteoblasts. Also, the inhibitory effect of PTH was blocked in the presence of $U$ equally in WT and $\mathrm{KO}$ cells (ABP vs ABUP, Fig. 5A and B, plans 1 and 2). By contrast, SB203580 (S), a p38/MAPK inhibitor, dramatically blocked basal mineralization by $\sim 70 \%$ and did not influence the inhibitory effect of PTH in early osteoblasts (Fig. 5A and B, plan 1). On the other hand, in the more mature cells, $S$ had no effect on basal mineralization and attenuated the inhibitory effect of PTH in both WT and KO osteoblasts (ABP vs ABSP, Fig. 5A and B, plan 2). These results suggest MKP1-independent regulation of ERK/MAPK and p38/MAPK in osteoblasts from male mice.

Figure 6 describes the results in osteoblasts derived from female WT (Fig. 6A) and KO (Fig. 6B) mice. In plan 1, osteoblasts from WT females showed similar results as observed in WT males. An increased tendency in basal mineralization in the presence of $U$ and significant downregulation $(\sim 50 \%)$ in the presence of $S$ was noted (AB vs ABU or ABS, Fig. 6A, plan 1). Also, the inhibitory effect of PTH was blocked in the presence of $U$ while presence of S did not influence PTH action (Fig. 6A, plan 1). By contrast, in MKP1 KO osteoblasts from females, PTH, as shown previously (Mahalingam et al. 2011), did 
A

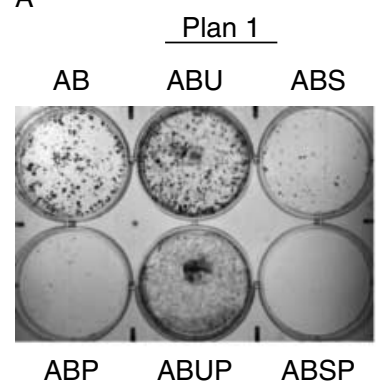

WT male

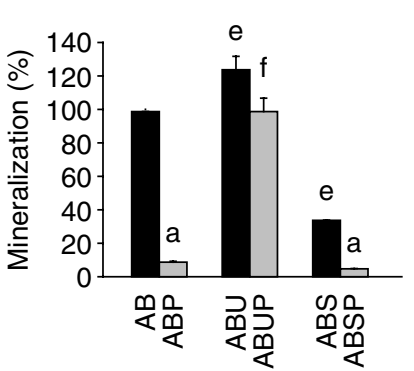

B

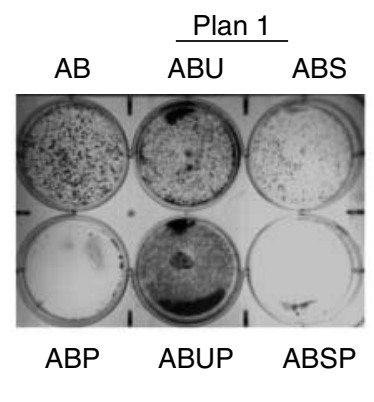

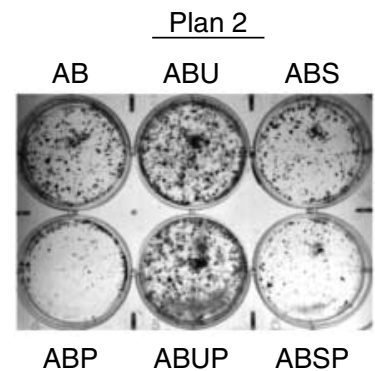

ABP

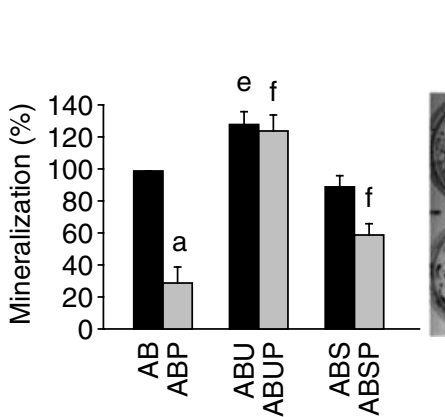

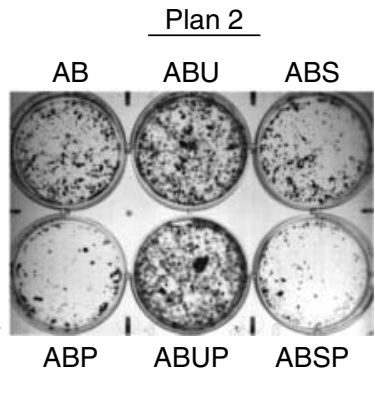

KO male

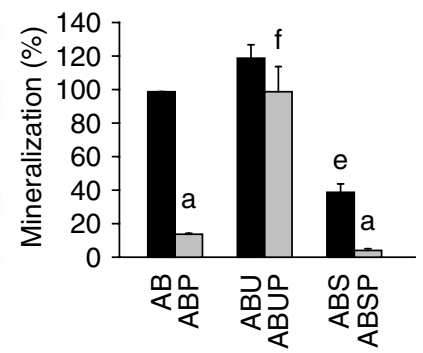

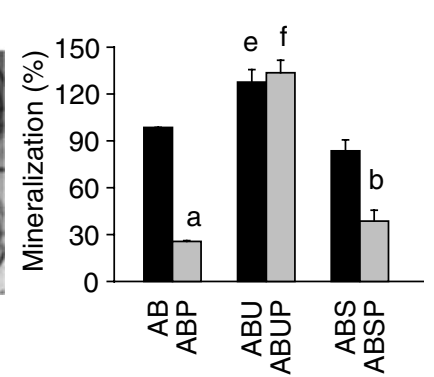

Figure 5

Involvement of MKP1, ERK, and p38 MAPK in PTH action on matrix mineralization in early and mature osteoblasts derived from male mice. Mineralized nodule formation was examined in osteoblasts derived from 11-14-week-old male (A) WT and (B) KO mice. von Kossa assay of mineralization was performed in early (plan 1) and mature (plan 2) osteoblasts as described in Fig. 4. Representative wells from three to four individual experiments with similar results for nodule formation are shown. The number of nodules were counted and plotted as $\%$ expression of nodules with respect to PTH-untreated cells. AB, differentiated cells without PTH or inhibitors; ABP, differentiated cells with PTH (P); $A B U$, differentiated cells with U0126 (U), an ERK inhibitor; ABUP, differentiated cells with $U$ and $P$; ABS, differentiated cells with SB203580 (S), a p38 inhibitor; $A B S P$, differentiated cells with $S$ and $P$. Values are expressed as mean \pm S.E.M. from three to four independent experiments $(n=2-3$ for male WT and KO mice in each experiment). ${ }^{a} P<0.001$ vs untreated with or without inhibitor; ${ }^{b} P<0.05$ vs untreated with or without inhibitor; ${ }^{\mathrm{e}} P<0.05$ vs untreated cells $(A B) ;{ }^{f} P<0.05$ vs $P T H$-treated cells (ABP). not inhibit mineralization in KO osteoblasts in plan 1 (Fig. $6 \mathrm{~B})$. In these cells, $\mathrm{U}$ alone did not influence basal mineralization while $S$ alone drastically diminished mineralization. Furthermore, the effect of PTH was blocked in the presence of $S$ but not in the presence of $U$ (Fig. 6B, plan 1). In more mature osteoblasts from WT females, effects of individual inhibitors or PTH alone showed only 15-20\% inhibition. The inhibitory effect was not altered in the presence of inhibitors (Fig. 6A, plan 2). Conversely, in KO osteoblasts from females, PTH inhibited (80\%) mineralization and this effect of PTH was blocked by $\mathrm{U}$ and not altered by S (Fig. 6B, plan 2). Taken together, these results suggested that p38 contribute to in vitro mineralization of osteoblasts. The disparate effect of PTH on osteoblast mineralization from female mice is MKP1 dependent involving maturation stage-specific P-ERK and P-p38 MAPKs.

\section{Roles of MKP1, P-p38, and P-ERK signaling on PTH regulation of Mgp expression in early vs mature osteoblasts}

Studies shown in Fig. 7 examined the effect of PTH on MGP expression in the presence or absence of MAPK inhibitors in early and mature osteoblasts from WT and MKP1 KO male (Fig. 7A) and female (Fig. 7B) mice. PTH treatment of osteoblasts derived from WT and $\mathrm{KO}$ male mice upregulated (approximately threefold) $M g p$ mRNA similarly in plans 1 and 2 (Fig. 7A). MGP expression was increased 4.5-fold in the presence of ERK inhibitor, $U$, in early WT osteoblasts and the effect of PTH was further increased in the presence of $U$ (Fig. 7A, plan 1). By contrast, the effect of PTH was blocked in the presence of $\mathrm{U}$ in $\mathrm{KO}$ osteoblasts (Fig. 7A, plan 1). In the presence of the p38 inhibitor, $S$, basal expression of MGP was increased 1.5- to 3-fold in WT and KO cells. Treatment

Published by Bioscientifica Ltd. 
A

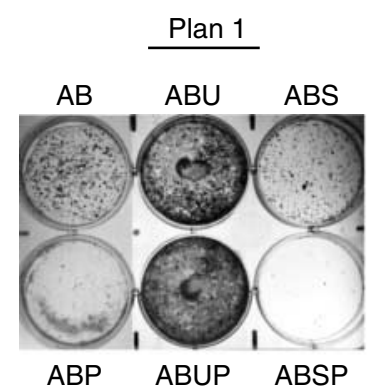

WT female
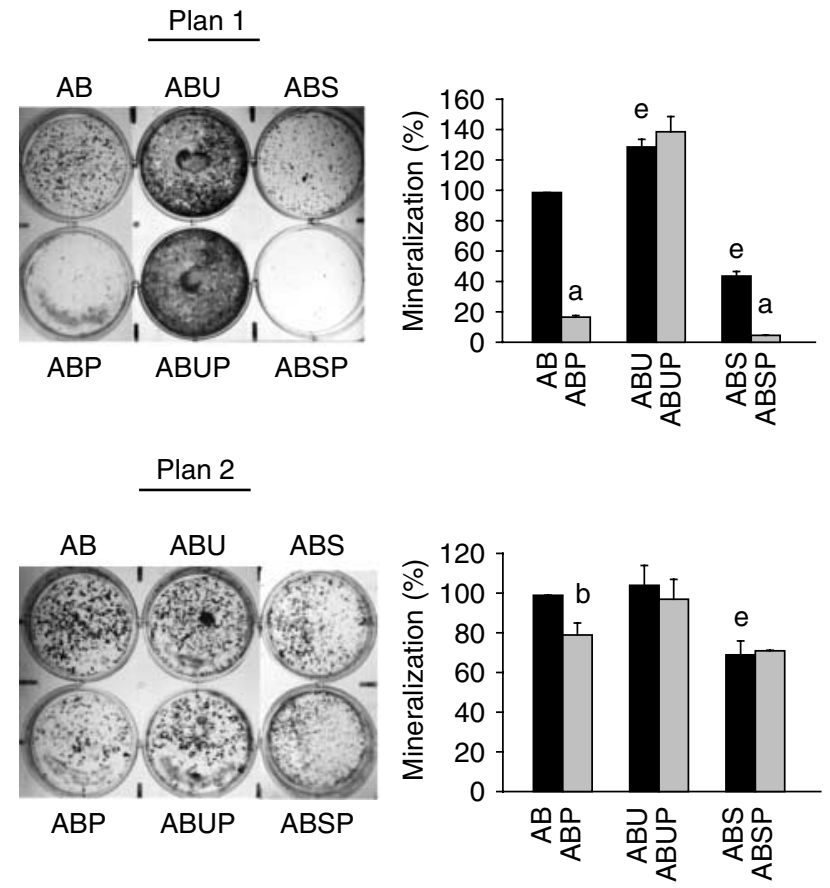

B
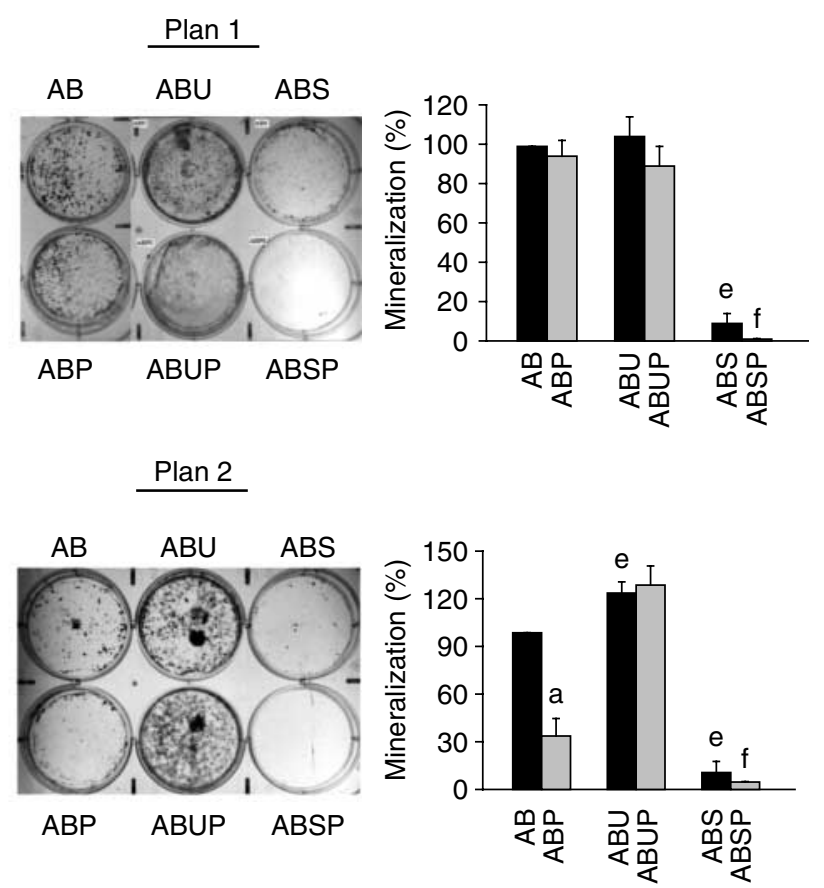

without PTH (P) or inhibitors; $A B P$, differentiated cells with PTH (P); $A B U$, differentiated cells with U0126 (U), an ERK inhibitor; ABUP, differentiated cells with U and P; ABS, differentiated cells with SB203580 (S), a p38 inhibitor; ABSP, differentiated cells with $S$ and $P$. Values are expressed as mean \pm S.E.M. from three to four independent experiments $(n=2-3$ for female WT and KO mice in each experiment). ${ }^{\mathrm{a}} P<0.001$ vs untreated with or without inhibitor; ${ }^{\mathrm{b}} P<0.05$ vs untreated with or without inhibitor; ${ }^{\mathrm{e}} P<0.05$ vs untreated cells (AB); ${ }^{\mathrm{f}} P<0.001$ vs $\mathrm{PTH}$-treated cells (ABP).

and plan 2). No significant effects of ERK inhibitor U were noted except that MGP expression was stimulated in the presence of $U$ alone and PTH in the presence of $U$ in mature KO osteoblasts (Fig. 7B, plan 2). Presence of p38 inhibitor, $\mathrm{S}$, increased (twofold) the basal expression of MGP in treatment plan 2 for WT cells (Fig. 7B). PTH in the presence of $S$ augmented (twofold) MGP expression in plan 1 (Fig. 7B), and no effect was observed in mature WT osteoblasts (Fig. 7B, plan 2). In the KO osteoblasts from females, $S$ alone did not influence basal expression in early osteoblasts and the effect of PTH remained unchanged in the presence of S (plan 1). However, MGP expression was increased approximately four- to fivefold in the presence of $S$ in mature KO cells. Although this effect was attenuated when cells were treated with PTH in the presence of S, MGP expression remained high compared with PTH alone (plan 2). http://joe.endocrinology-journals.org DOI: 10.1530/JOE-12-0372
(๑) 2013 Society for Endocrinology Printed in Great Britain 
A

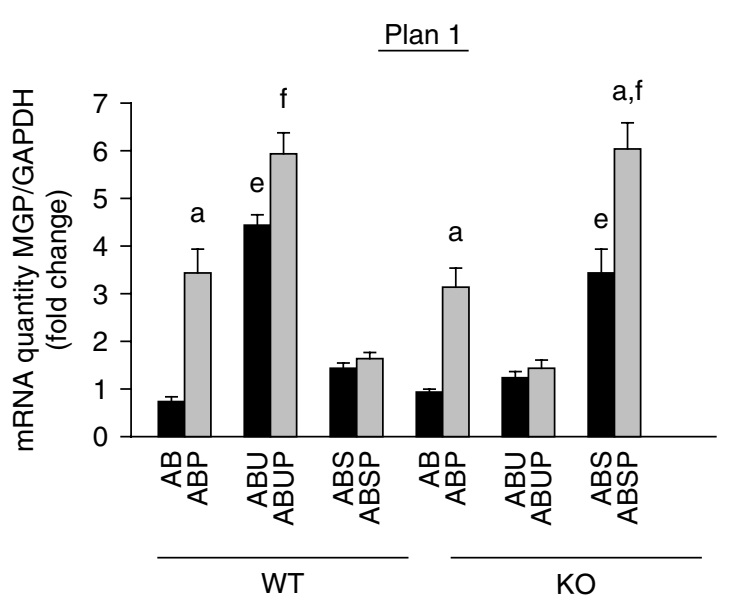

Plan 2

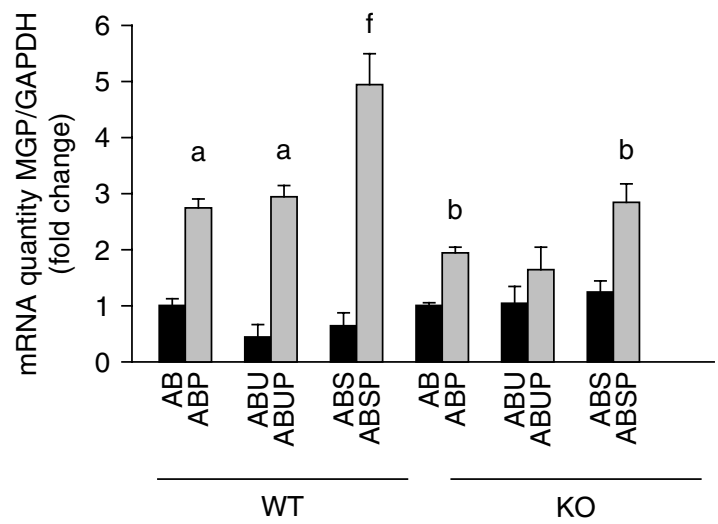

Figure 7

Involvement of MKP1, ERK, and p38 MAPK in PTH action on MGP expression in early and mature osteoblasts derived from male and female mice. Osteoblasts derived from 11-14-week-old (A) male and (B) female WT and KO mice were subjected to two treatment plans as described in Fig. 4. Total RNA was isolated from cultures at day 15 with and without inhibitors and/or PTH treatment, and Mgp mRNA expression was quantified by realtime PCR analysis as described in Materials and methods section. Results are graphically represented after normalization with GAPDH as fold change with respect to PTH-untreated differentiated cells. AB, differentiated cells

\section{Discussion}

In this study, we observed increased proliferation of calvarial osteoblasts obtained from either male or female MKP1 KO mice. This is consistent with a preliminary report using bone marrow stromal cells from male $\mathrm{KO}$ mice (Ma et al. 2009). Continued proliferation of $\mathrm{KO}$ osteoblasts from female mice beyond 10 days in culture when proliferation plateaued in osteoblasts from $\mathrm{KO}$ males suggested differences in MKP1 regulation and
B Female

$\underline{\text { Plan } 1}$

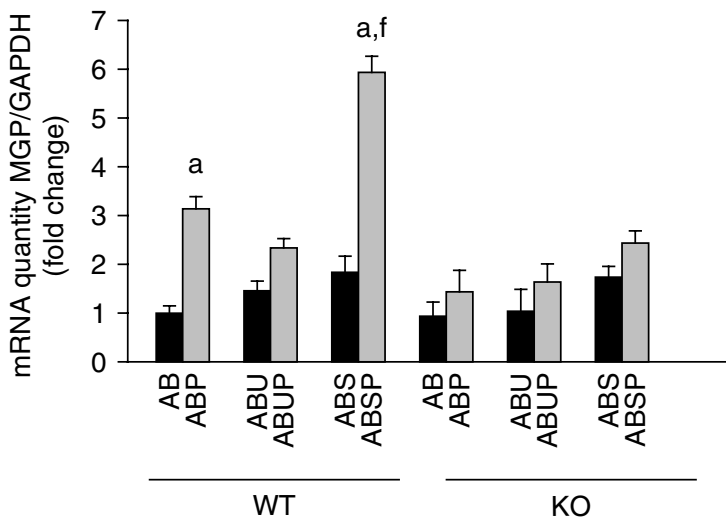

Plan 2

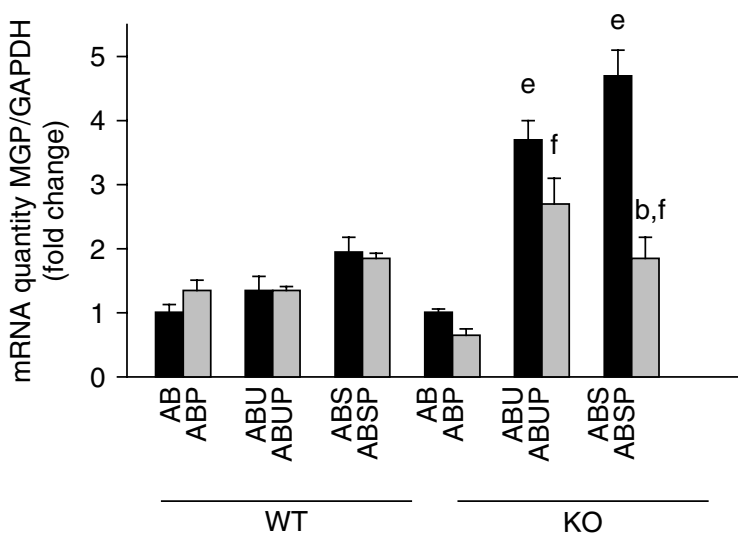

without PTH (P) or inhibitors; $A B P$, differentiated cells with PTH (P); $A B U$, differentiated cells with U0126 (U), an ERK inhibitor; ABUP, differentiated cells with $U$ and $P ; A B S$, differentiated cells with SB203580 (S), a p38 inhibitor; $A B S P$, differentiated cells with $S$ and $P$. Values are expressed as mean \pm s.E.M. from three independent experiments $(n=2-3$ for female WT and KO mice in each experiment). ${ }^{\mathrm{a}} P<0.001$ vs untreated with or without inhibitor; ${ }^{\mathrm{b}} P<0.05$ vs untreated with or without inhibitor; ${ }^{\mathrm{e}} P<0.01$ vs untreated cells (AB); ${ }^{\mathrm{f}} P<0.05$ vs PTH treated cells (ABP).

MAPK activation between cells from different genders. Sex-related differences in MAPK activation and cell proliferation/survival of rat astrocytes, rat cardiomyocytes, or mouse liver have been previously reported (Nuedling et al. 1999, Zhang et al. 2002, Vilatoba et al. 2005). Selective modulation of MAPKs was suggested to be involved in gender-based differences in cardiac diseases (Nuedling et al. 1999) and in cardioprotection (Vilatoba et al. 2005). It was also suggested that regulation of MAPKs

Published by Bioscientifica Ltd. 
may result in differential regulation of cell proliferation and death in astrocytes and possibly contributes to sexual dimorphisms in brain development (Zhang et al. 2002).

MAPKs regulate cyclin D1 (Terada et al. 1999), an unique regulator of cell cycle progression and cell proliferation (Sherr \& Roberts 2004, Gladden \& Diehl 2005, Musgrove 2006). The disparate regulation of P-ERK, P-p38 MAPKs, and cyclin D1 in male and female MKP1 KO osteoblasts in this study implies that cyclin D1 and other canonical regulators of the G1/S transition coordinate key players of cell cycle progression to achieve the sexually dimorphic cell division (Tilmann \& Kimble 2005) and PTH response in osteoblasts. In spite of the very wellestablished role of cyclin D1-CDK4/6 in the cell cycle, cyclin D1 may perform CDK-independent functions by binding, activating, or repressing several transcription factors including DMP1 (Inoue \& Sherr 1998), STAT3 (Bienvenu et al. 2001), and hormone receptors such as estrogen receptor (McMahon et al. 1999, Lamb et al. 2000), androgen receptor (Reutens et al. 2001, Petre et al. 2002), and thyroid hormone receptor (Lin et al. 2002) in a liganddependent or -independent manner. Among other transcription factors, Jun B, a member of the AP-1 family, regulates cell proliferation and differentiation (Piechaczyk $\&$ Farras 2008). Previous work by us demonstrated that posttranslational stabilization of Jun B by decreased phosphorylation leads to differential expression of cyclin D1 protein and growth arrest in MC3T3-E1 osteoblastic cells (Datta et al. 2005). Furthermore, novel function of JunB as a regulator of osteoclast and osteoblast activities in osteopenia has been reported (Kenner et al. 2004). Future studies involving receptors of estrogen, androgen, and/or PTH with AP-I transcription factors, MKP1, MAPKs, and cell cycle machinery in bone cells are necessary to substantiate our hypothesis on regulation by PTH.

Both magnitude and duration of MAPK activity are responsible for a number of physiological responses (Marshall 1995, Ebisuya et al. 2005). Using primary osteoblasts and pharmacological inhibitors, our studies demonstrate that p38 MAPK is required for in vitro matrix mineralization in both early and mature osteoblasts. This is in agreement with previous studies by $\mathrm{Hu}$ et al. (2003) using osteoblastic cells in vitro and with a recent report showing that cells derived from osteoblast-specific p38 KO mice have defective mineralization in vitro, reduced endocortical and trabecular bone formation, and decreased expression of osteoblast differentiation marker genes (Thouverey \& Caverzasio 2012). We also observed a tendency toward increased osteoblast mineralization when P-ERK activation was blocked, irrespective of osteoblast differentiation stage. Interestingly, recent evidence suggests that chronic inhibition of ERK signaling decreases unmineralized osteoid volume and increased mineralization of trabecular and cortical bone in hypophosphatemic mice (Zhang et al. 2012). Collectively, these findings and our observation provide evidence that p38 and ERK MAPKs have opposite roles in osteoblast mineralization. Activation of p38 MAPK is critical for calcification of bone matrix from early to late stages of differentiation and inhibition of ERK-MAPK improves mineralization of osteoblasts.

Our novel findings include the dependency of MKP1 signaling on PTH regulation of primary osteoblast mineralization. Consistent with the report that continuous PTH administration inhibits mineralization of osteoblasts in vitro (Gopalakrishnan et al. 2005), we observed inhibition of mineralization with PTH in early and mature osteoblasts derived from WT or MKP1 KO males and this effect of PTH was dependent on ERK, not on p38. The inhibitory effect of PTH on osteoblast mineralization in WT females in early osteoblasts was not replicated when PTH treatment was initiated in more mature cells. Furthermore, we observe an opposite effect of PTH in osteoblasts derived from $\mathrm{KO}$ females showing continued mineralization in early osteoblast and decreased mineralization in more mature cells when compared with respective WT females. Taken together, these studies show that the effect of PTH on mineralization of osteoblasts from female mice is MKP1 dependent and involves p38 MAPK in early osteoblasts and ERK-MAPK in more mature cells. Thus, MKP1-dependent disparate regulation of PTH in female osteoblasts is maturation stage specific. The involvement of p38 MAPK in PTH regulation of mineralization (Rey et al. 2007) was only obvious in early osteoblasts derived from MKP1 KO females. We do not know the biological relevance of this disparate response at the present time. Perhaps PTH regulation of mineralization requires continuous presence of MKP1; thus, it could regulate MAPK pathway activities at various stages of differentiation. This is supported by the fact that PTH regulation of osteoblast differentiation and molecular action is maturation stage specific (Datta et al. 2005, 2007, 2010a).

Commitment to the mature osteoblast stage is confirmed by the upregulation of mineralization genes (Hartmann 2009). MGP is regulated by PTH, FGF, and ERK MAPK in osteoblasts (Gopalakrishnan et al. 2005, Khoshniat et al. 2011, Kyono et al. 2012). We hypothesized that modulation of MGP expression with PTH and/or MAPK inhibitors would correlate mineralization in WT and

Published by Bioscientifica Ltd 


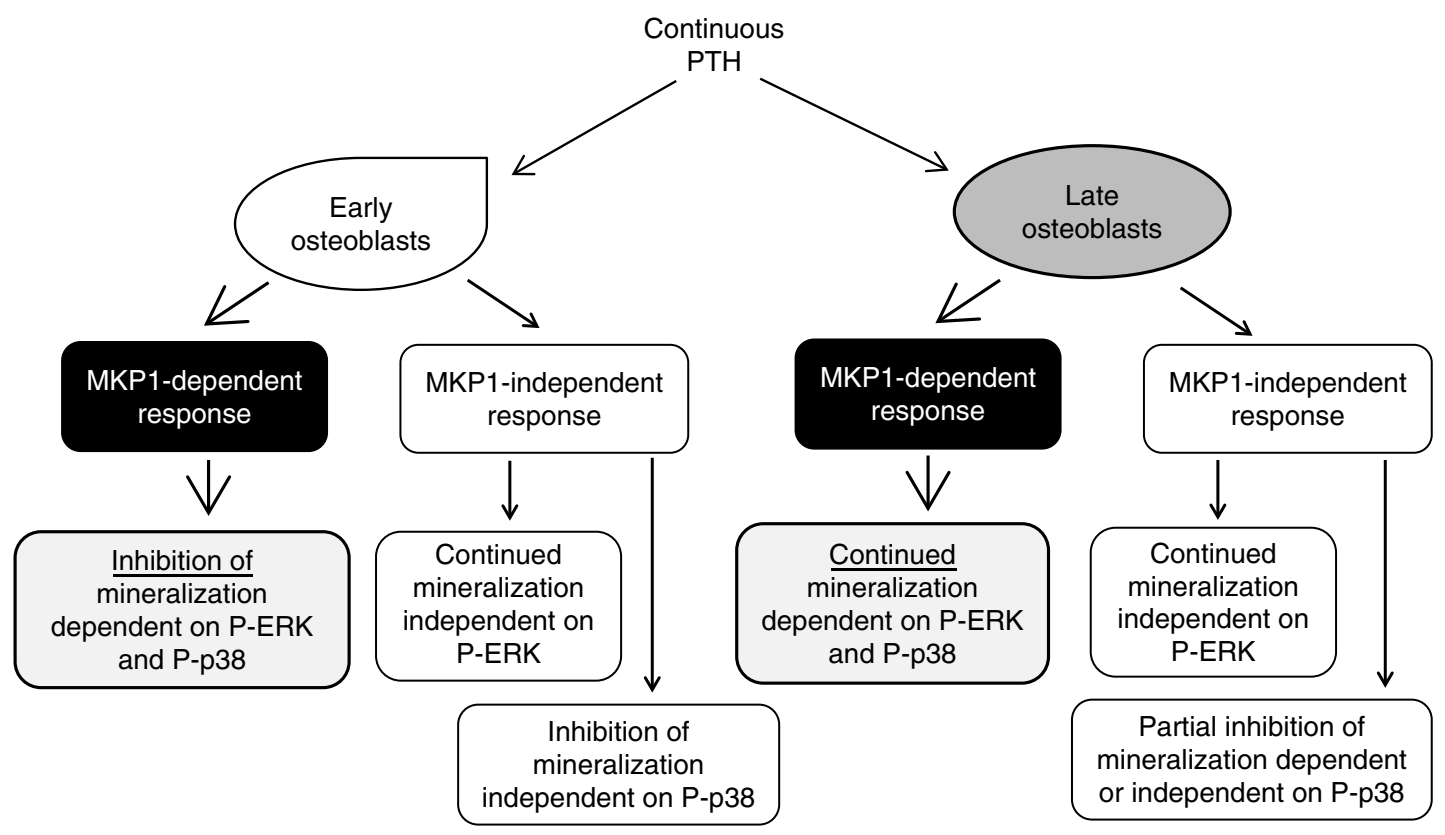

\section{Figure 8}

Hypothetical responses to PTH signal and P-ERK-mediated and P-p38-mediated matrix mineralization of osteoblasts derived from female mice. Both MKP1-dependent and MKP1-independent responses of

MKP1 KO osteoblasts at different stages of maturation. However, our data using the present experimental conditions did not show such a correlation. Differentiation-dependent hormonal regulation of MGP has been suggested during chondrogenesis and osteogenesis in rat (Barone et al. 1991). Two conclusions may be drawn from this study: first, critical changes at the molecular level occur at the earlier stages of the differentiation process, particularly in the presence or absence of MAPKs and MKP1, and these changes influence MGP expression without any association with mineralization. Secondly, although MGP is a major regulator of PTH inhibition of mineralization (Gopalakrishnan et al. 2005), MKP1, P-ERK, and p38 MAPKs govern this process via additional mechanisms unrelated to MGP. Collectively, our observations suggest that MKP1 signaling coordinately with cell maturation stage regulates mineralization in the osteoblast lineage and that MKP1, ERK, and p38 signaling is essential for PTH action on mineralization in addition to regulation of MGP expression.

At the present time, the physiological and pathological significance of the MKP1-dependent maturation stage-specific effect of PTH are not known. Timely activation/inactivation of MAPKs is essential for the
ERK/MAPK and p38/MAPK to PTH are proposed in early and late osteoblasts. Major responses are depicted by large arrows.

generation of appropriate cellular outcomes and for restoration of responsiveness. Studies suggest that c-Raf regulates ERK activity at an earlier time point and MKP1 may contribute to the regulation over a prolonged period of time (Lai \& Mitchell 2009). Thus, time course is critical in this regulation. The current study provides important evidence of sexual dimorphism even in vitro, indicating that MKP1 plays a relevant role in the maintenance of skeletal homeostasis in female mice. The mechanism by which gender influences cortical bone size may be overly complicated and is still a matter of investigation. Evidence shows that skeletal dimorphism is dependent on timespecific effects of sex steroids and GH-insulin-like growth factor 1 (GH-IGF1; Callewaert et al. 2010). Interaction of IGF1 and ERK (Perrini et al. 2008) may alter osteoblast proliferation and mineralization response. Sexually dimorphic behavior may therefore arise from finely tuned modifications at every level of different signaling cascades.

It should be pointed out that change in MKP1 expression (Datta et al. 2010a) is only one aspect of the highly complex osteoblast response to PTH. This response also involves the induction of several modulators of osteoblast signaling in addition to MKP1. However, these studies clearly suggest that MKP1 plays an important role

Published by Bioscientifica Ltd. 
during the differentiation process and matrix mineralization. We propose that PTH control of osteoblast mineralization involves more than one pathway, which may be MKP1-dependent ERK/p38 signaling, or MKP1independent ERK/pp38 signaling (Fig. 8). At present, it is not known to what extent other phosphatases contribute to the osteoblast differentiation pathway and at what levels MKP1-mediated regulation of MAPKs influences osteoblast differentiation and mineralization gene expression.

MKPs differentially recognize, bind, and dephosphorylate MAPKs to integrate MAPK signaling (Owens \& Keyse 2007). Some details of the molecular mechanism involved in MKPs and MAPKs in regulating specific functions, e.g. regulation of immune function is partially understood (Zhang et al. 2004, 2005, Chi et al. 2006). However, there remains considerable complexity despite the apparent specificity for ERK and p38 (Jeffrey et al. 2006). Considering the perplexity of this network, comprehensive understanding of MKPs function, in bone biology will require extensive future investigations. Nevertheless, in conclusion, our studies provide evidence that the MKP1-P-p38 and MKP1-P-ERK circuits play important roles in controlling the balance between osteoblast maturation, function/mineralization, and PTH signal transduction. Understanding the role of MKP1 in the anabolic activities of bone in female mice may lead to the identification of potentially novel therapeutic targets to reduce the risk of postmenopausal osteoporosis.

\section{Declaration of interest}

The authors declare that there is no conflict of interest that could be perceived as prejudicing the impartiality of the research reported.

\section{Funding}

This work was supported by funding from WSU OVPR and NIH DK087848 to N S D.

\section{Acknowledgements}

MKP1 KO mice were obtained through Material Transfer Agreement between Bristol-Myers Squibb and NSD (Wayne State University [WSU]). Acknowledgement is due to animal care facilities, Division of Laboratory and Animal Research, WSU, for taking care of our mice, and Alemu Fite for assistance with mice handling.

\section{References}

Barone LM, Owen TA, Tassinari MS, Bortell R, Stein GS \& Lian JB 1991 Developmental expression and hormonal regulation of the rat matrix Gla protein (MGP) gene in chondrogenesis and osteogenesis. Journal of Cellular Biochemistry 46 351-365. (doi:10.1002/jcb.240460410)
Bienvenu F, Gascan H \& Coqueret O 2001 Cyclin D1 represses STAT3 activation through a Cdk4-independent mechanism. Journal of Biological Chemistry 276 16840-16847. (doi:10.1074/jbc.M100795200)

Bikle DD \& Wang Y 2012 Insulin like growth factor-I: a critical mediator of the skeletal response to parathyroid hormone. Current Molecular Pharmacology 5 135-142.

Callewaert F, Venken K, Kopchick JJ, Torcasio A, van Lenthe GH, Boonen S \& Vanderschueren D 2010 Sexual dimorphism in cortical bone size and strength but not density is determined by independent and timespecific actions of sex steroids and IGF-1: evidence from pubertal mouse models. Journal of Bone and Mineral Research 25 617-626. (doi:10.1359/ jbmr.090828)

Cappuzzo KA \& Delafuente JC 2004 Teriparatide for severe osteoporosis. Annals of Pharmacotherapy 38 294-302. (doi:10.1345/aph.1D353)

Carlson J, Cui W, Zhang Q, Xu X, Mercan F, Bennett AM \& Vignery A 2009 Role of MKP-1 in osteoclasts and bone homeostasis. American Journal of Pathology 175 1564-1573. (doi:10.2353/ajpath.2009.090035)

Chen C, Koh AJ, Datta NS, Zhang J, Keller ET, Xiao G, Franceschi RT, D'Silva NJ \& McCauley LK 2004 Impact of the mitogen-activated protein kinase pathway on parathyroid hormone-related protein actions in osteoblasts. Journal of Biological Chemistry 279 29121-29129. (doi:10.1074/jbc.M313000200)

Chi H, Barry SP, Roth RJ, Wu JJ, Jones EA, Bennett AM \& Flavell RA 2006 Dynamic regulation of pro- and anti-inflammatory cytokines by MAPK phosphatase 1 (MKP-1) in innate immune responses. PNAS 103 2274-2279. (doi:10.1073/pnas.0510965103)

Datta NS 2011 Osteoporotic fracture and parathyroid hormone. World Journal of Orthopedics 2 67-74. (doi:10.5312/wjo.v2.i8.67)

Datta NS \& Abou-Samra AB 2009 PTH and PTHrP signaling in osteoblasts. Cellular Signalling 21 1245-1254. (doi:10.1016/j.cellsig.2009.02.012)

Datta NS, Chen C, Berry JE \& McCauley LK 2005 PTHrP signaling targets cyclin D1 and induces osteoblastic cell growth arrest. Journal of Bone and Mineral Research 20 1051-1064. (doi:10.1359/JBMR.050106)

Datta NS, Pettway GJ, Chen C, Koh AJ \& McCauley LK 2007 Cyclin D1 as a target for the proliferative effects of PTH and PTHrP in early osteoblastic cells. Journal of Bone and Mineral Research 22 951-964. (doi:10.1359/ jbmr.070328)

Datta NS, Kolailat R, Fite A, Pettway G \& Abou-Samra AB $2010 a$ Distinct roles for mitogen-activated protein kinase phosphatase-1 (MKP-1) and ERK-MAPK in PTH1R signaling during osteoblast proliferation and differentiation. Cellular Signalling 22 457-466. (doi:10.1016/j.cellsig. 2009.10.017)

Datta NS, Samra TA, Mahalingam CD, Datta T \& Abou-Samra AB 2010 $b$ Role of PTH1R internalization in osteoblasts and bone mass using a phosphorylation-deficient knock-in mouse model. Journal of Endocrinology 207 355-365. (doi:10.1677/JOE-10-0227)

Datta NS, Samra TA \& Abou-Samra AB 2012 Parathyroid hormone (PTH) induces bone formation in phosphorylation deficient PTHR1 knock-in mice. American Journal of Physiology. Endocrinology and Metabolism 302 E1183-E1188. (doi:10.1152/ajpendo.00380.2011)

Dominguez LJ, Di Bella G, Belvedere M \& Barbagallo M 2011 Physiology of the aging bone and mechanisms of action of bisphosphonates. Biogerontology 12 397-408. (doi:10.1007/s10522-011-9344-5)

Dong C, Davis RJ \& Flavell RA 2002 MAP kinases in the immune response. Annual Review of Immunology 20 55-72. (doi:10.1146/annurev.immunol.20.091301.131133)

Dorfman K, Carrasco D, Gruda M, Ryan C, Lira SA \& Bravo R 1996 Disruption of the erp/mkp-1 gene does not affect mouse development: normal MAP kinase activity in ERP/MKP-1-deficient fibroblasts. Oncogene 13 925-931.

Ebisuya M, Kondoh K \& Nishida E 2005 The duration, magnitude and compartmentalization of ERK MAP kinase activity: mechanisms for providing signaling specificity. Journal of Cell Science 118 2997-3002. (doi:10.1242/jcs.02505)

Fei Y \& Hurley MM 2012 Role of fibroblast growth factor 2 and Wnt signaling in anabolic effects of parathyroid hormone on bone 
formation. Journal of Cellular Physiology 227 3539-3545. (doi:10.1002/ jcp.24075)

Feng X \& McDonald JM 2011 Disorders of bone remodeling. Annual Review of Pathology 6 121-145. (doi:10.1146/annurev-pathol-011110-130203)

Gladden AB \& Diehl JA 2005 Location, location, location: the role of cyclin D1 nuclear localization in cancer. Journal of Cellular Biochemistry 96 906-913. (doi:10.1002/jcb.20613)

Gopalakrishnan R, Ouyang H, Somerman MJ, McCauley LK \& Franceschi RT 2001 Matrix gamma-carboxyglutamic acid protein is a key regulator of PTH-mediated inhibition of mineralization in MC3T3-E1 osteoblast-like cells. Endocrinology 142 4379-4388. (doi:10.1210/en.142.10.4379)

Gopalakrishnan R, Suttamanatwong S, Carlson AE \& Franceschi RT 2005 Role of matrix Gla protein in parathyroid hormone inhibition of osteoblast mineralization. Cells, Tissues, Organs 181 166-175. (doi:10.1159/000091378)

Greenfield EM 2012 Anabolic effects of intermittent PTH on osteoblasts. Current Molecular Pharmacology 5 127-134.

Hartmann C 2009 Transcriptional networks controlling skeletal development. Current Opinion in Genetics \& Development 19 437-443. (doi:10.1016/j.gde.2009.09.001)

$\mathrm{Hu}$ Y, Chan E, Wang SX \& Li B 2003 Activation of p38 mitogen-activated protein kinase is required for osteoblast differentiation. Endocrinology 144 2068-2074. (doi:10.1210/en.2002-220863)

Inoue K \& Sherr CJ 1998 Gene expression and cell cycle arrest mediated by transcription factor DMP1 is antagonized by D-type cyclins through a cyclin-dependent-kinase-independent mechanism. Molecular and Cellular Biology 18 1590-1600.

Jeffrey KL, Brummer T, Rolph MS, Liu SM, Callejas NA, Grumont RJ, Gillieron C, Mackay F, Grey S, Camps M et al. 2006 Positive regulation of immune cell function and inflammatory responses by phosphatase PAC-1. Nature Immunology 7 274-283. (doi:10.1038/ni1310)

Kenner L, Hoebertz A, Beil T, Keon N, Karreth F, Eferl R, Scheuch H, Szremska A, Amling M, Schorpp-Kistner M et al. 2004 Mice lacking JunB are osteopenic due to cell-autonomous osteoblast and osteoclast defects. Journal of Cell Biology 164 613-623. (doi:10.1083/jcb. 200308155)

Khoshniat S, Bourgine A, Julien M, Petit M, Pilet P, Rouillon T, Masson M, Gatius M, Weiss P, Guicheux J et al. 2011 Phosphate-dependent stimulation of MGP and OPN expression in osteoblasts via the ERK1/2 pathway is modulated by calcium. Bone 48 894-902. (doi:10.1016/j. bone.2010.12.002)

Khosla S \& Riggs BL 2005 Pathophysiology of age-related bone loss and osteoporosis. Endocrinology and Metabolism Clinics of North America 34 1015-1030, xi. (doi:10.1016/j.ecl.2005.07.009)

Khosla S, Bilezikian JP, Dempster DW, Lewiecki EM, Miller PD, Neer RM, Recker RR, Shane E, Shoback D \& Potts JT 2012 Benefits and risks of bisphosphonate therapy for osteoporosis. Journal of Clinical Endocrinology and Metabolism 97 2272-2282. (doi:10.1210/jc.2012-1027)

Kostenuik PJ, Harris J, Halloran BP, Turner RT, Morey-Holton ER \& Bikle DD 1999 Skeletal unloading causes resistance of osteoprogenitor cells to parathyroid hormone and to insulin-like growth factor-I. Journal of Bone and Mineral Research 14 21-31. (doi:10.1359/jbmr.1999.14.1.21)

Kular J, Tickner J, Chim SM \& Xu J 2012 An overview of the regulation of bone remodelling at the cellular level. Clinical Biochemistry 45 863-873. (doi:10.1016/j.clinbiochem.2012.03.021)

Kyono A, Avishai N, Ouyang Z, Landreth GE \& Murakami S 2012 FGF and ERK signaling coordinately regulate mineralization-related genes and play essential roles in osteocyte differentiation. Journal of Bone and Mineral Metabolism 30 19-30. (doi:10.1007/s00774-011-0288-2)

Lai LP \& Mitchell J 2009 Parathyroid hormone inhibits phosphorylation of mitogen-activated protein kinase (MAPK) ERK1/2 through inhibition of c-Raf and activation of MKP-1 in osteoblastic cells. Cell Biochemistry and Function 27 269-275. (doi:10.1002/cbf.1568)

Lamb J, Ladha MH, McMahon C, Sutherland RL \& Ewen ME 2000 Regulation of the functional interaction between cyclin D1 and the estrogen receptor. Molecular and Cellular Biology 20 8667-8675. (doi:10.1128/MCB.20.23.8667-8675.2000)

Lin HM, Zhao L \& Cheng SY 2002 Cyclin D1 is a ligand-independent co-repressor for thyroid hormone receptors. Journal of Biological Chemistry 277 28733-28741. (doi:10.1074/jbc.M203380200)

Lombardi G, Di Somma C, Vuolo L, Guerra E, Scarano E \& Colao A 2010 Role of IGF-I on PTH effects on bone. Journal of Endocrinological Investigation 33 22-26.

Ma L, Choudhary S, Voznesensky O, Raisz L \& Pilbeam C 2009 Effects of MKP-1 deletion on osteoblast growth and differentiation. In American Society of Bone and Mineral Research (ASBMR), p MO 0186. Denver, CO.

Mahalingam CD, Datta T, Patil RV, Kreider J, Bonfil RD, Kirkwood KL, Goldstein SA, Abou-Samra AB \& Datta NS 2011 Mitogen activated protein kinase phosphatase-1 regulates bone mass, osteoblast gene expression, and responsiveness to parathyroid hormone. Journal of Endocrinology 211 145-156. (doi:10.1530/JOE-11-0144)

Manolagas SC 2000 Birth and death of bone cells: basic regulatory mechanisms and implications for the pathogenesis and treatment of osteoporosis. Endocrine Reviews 21 115-137. (doi:10.1210/er.21.2.115)

Marsh ME, Munne AM, Vogel JJ, Cui Y \& Franceschi RT 1995 Mineralization of bone-like extracellular matrix in the absence of functional osteoblasts. Journal of Bone and Mineral Research 10 1635-1643. (doi:10.1002/jbmr.5650101105)

Marshall CJ 1995 Specificity of receptor tyrosine kinase signaling: transient versus sustained extracellular signal-regulated kinase activation. Cell 80 179-185. (doi:10.1016/0092-8674(95)90401-8)

McMahon C, Suthiphongchai T, DiRenzo J \& Ewen ME 1999 P/CAF associates with cyclin D1 and potentiates its activation of the estrogen receptor. PNAS 96 5382-5387. (doi:10.1073/pnas.96.10.5382)

Miller PD, Bilezikian JP, Diaz-Curiel M, Chen P, Marin F, Krege JH, Wong M \& Marcus R 2007 Occurrence of hypercalciuria in patients with osteoporosis treated with teriparatide. Journal of Clinical Endocrinology and Metabolism 92 3535-3541. (doi:10.1210/jc.2006-2439)

Musgrove EA 2006 Cyclins: roles in mitogenic signaling and oncogenic transformation. Growth Factors 24 13-19. (doi:10.1080/ 08977190500361812)

Nishida S, Yamaguchi A, Tanizawa T, Endo N, Mashiba T, Uchiyama Y, Suda T, Yoshiki S \& Takahashi HE 1994 Increased bone formation by intermittent parathyroid hormone administration is due to the stimulation of proliferation and differentiation of osteoprogenitor cells in bone marrow. Bone 15 717-723. (doi:10.1016/8756-3282(94)90322-0)

Nuedling S, Kahlert S, Loebbert K, Meyer R, Vetter H \& Grohe C 1999 Differential effects of $17 \beta$-estradiol on mitogen-activated protein kinase pathways in rat cardiomyocytes. FEBS Letters 454 271-276. (doi:10.1016/S0014-5793(99)00816-9)

Owens DM \& Keyse SM 2007 Differential regulation of MAP kinase signalling by dual-specificity protein phosphatases. Oncogene $\mathbf{2 6}$ 3203-3213. (doi:10.1038/sj.onc.1210412)

Perrini S, Natalicchio A, Laviola L, Cignarelli A, Melchiorre M, De Stefano F, Caccioppoli C, Leonardini A, Martemucci S, Belsanti G et al. 2008 Abnormalities of insulin-like growth factor-I signaling and impaired cell proliferation in osteoblasts from subjects with osteoporosis. Endocrinology 149 1302-1313. (doi:10.1210/en.2007-1349)

Petre CE, Wetherill YB, Danielsen M \& Knudsen KE 2002 Cyclin D1: mechanism and consequence of androgen receptor co-repressor activity. Journal of Biological Chemistry 277 2207-2215. (doi:10.1074/ jbc.M106399200)

Piechaczyk M \& Farras R 2008 Regulation and function of JunB in cell proliferation. Biochemical Society Transactions 36 864-867. (doi:10.1042/BST0360864)

Qin L, Raggatt LJ \& Partridge NC 2004 Parathyroid hormone: a doubleedged sword for bone metabolism. Trends in Endocrinology and Metabolism 15 60-65. (doi:10.1016/j.tem.2004.01.006)

Raisz LG 2005 Pathogenesis of osteoporosis: concepts, conflicts, and prospects. Journal of Clinical Investigation 115 3318-3325. (doi:10.1172/ JCI27071) 
Reutens AT, Fu M, Wang C, Albanese C, McPhaul MJ, Sun Z, Balk SP, Janne OA, Palvimo JJ \& Pestell RG 2001 Cyclin D1 binds the androgen receptor and regulates hormone-dependent signaling in a p300/CBPassociated factor (P/CAF)-dependent manner. Molecular Endocrinology 15 797-811. (doi:10.1210/me.15.5.797)

Rey A, Manen D, Rizzoli R, Ferrari SL \& Caverzasio J 2007 Evidences for a role of p38 MAP kinase in the stimulation of alkaline phosphatase and matrix mineralization induced by parathyroid hormone in osteoblastic cells. Bone 41 59-67. (doi:10.1016/j.bone.2007.02.031)

Sherr CJ \& Roberts JM 2004 Living with or without cyclins and cyclindependent kinases. Genes and Development 18 2699-2711. (doi:10.1101/ gad.1256504)

Silva BC, Costa AG, Cusano NE, Kousteni S \& Bilezikian JP 2011 Catabolic and anabolic actions of parathyroid hormone on the skeleton. Journal of Endocrinological Investigation 34 801-810.

Stein GS \& Lian JB 1993 Molecular mechanisms mediating developmental and hormone-regulated expression of genes in osteoblasts: an integrated relationship of cell growth and differentiation. In Cellular and Molecular Biology of Bone, pp 47-95. Ed M Noda. Tokyo: Academic Press.

Terada Y, Inoshita S, Nakashima O, Kuwahara M, Sasaki S \& Marumo F 1999 Regulation of cyclin D1 expression and cell cycle progression by mitogen-activated protein kinase cascade. Kidney International $\mathbf{5 6}$ 1258-1261. (doi:10.1046/j.1523-1755.1999.00704.x)

Thouverey C \& Caverzasio J 2012 The p38alpha MAPK positively regulates osteoblast function and postnatal bone acquisition. Cellular and Molecular Life Sciences 69 3115-3125. (doi:10.1007/s00018-012-0983-8)

Tilmann C \& Kimble J 2005 Cyclin D regulation of a sexually dimorphic asymmetric cell division. Developmental Cell 9 489-499. (doi:10.1016/ j.devcel.2005.09.004)

Vilatoba M, Eckstein C, Bilbao G, Frennete L, Eckhoff DE \& Contreras JL $200517 \beta$-Estradiol differentially activates mitogen-activated proteinkinases and improves survival following reperfusion injury of reducedsize liver in mice. Transplantation Proceedings 37 399-403. (doi:10.1016/ j.transproceed.2004.12.053)
Wada T \& Penninger JM 2004 Mitogen-activated protein kinases in apoptosis regulation. Oncogene 23 2838-2849. (doi:10.1038/sj.onc. 1207556)

Xiao G, Gopalakrishnan R, Jiang D, Reith E, Benson MD \& Franceschi RT 2002 Bone morphogenetic proteins, extracellular matrix, and mitogenactivated protein kinase signaling pathways are required for osteoblastspecific gene expression and differentiation in MC3T3-E1 cells. Journal of Bone and Mineral Research 17 101-110. (doi:10.1359/jbmr. 2002.17.1.101)

Yu EW, Kumbhani R, Siwila-Sackman E \& Leder BZ 2011 Acute decline in serum sclerostin in response to PTH infusion in healthy men. Journal of Clinical Endocrinology and Metabolism 96 E1848-E1851. (doi:10.1210/jc. 2011-1534)

Zhang L, Li B, Zhao W, Chang YH, Ma W, Dragan M, Barker JL, Hu Q \& Rubinow DR 2002 Sex-related differences in MAPKs activation in rat astrocytes: effects of estrogen on cell death. Brain Research. Molecular Brain Research 103 1-11. (doi:10.1016/S0169-328X(02)00130-4)

Zhang Y, Blattman JN, Kennedy NJ, Duong J, Nguyen T, Wang Y, Davis RJ, Greenberg PD, Flavell RA \& Dong C 2004 Regulation of innate and adaptive immune responses by MAP kinase phosphatase 5. Nature $\mathbf{4 3 0}$ 793-797. (doi:10.1038/nature02764)

Zhang Q, Muller M, Chen CH, Zeng L, Farooq A \& Zhou MM 2005 New insights into the catalytic activation of the MAPK phosphatase PAC-1 induced by its substrate MAPK ERK2 binding. Journal of Molecular Biology 354 777-788. (doi:10.1016/j.jmb.2005.10.006)

Zhang MY, Ranch D, Pereira RC, Armbrecht HJ, Portale AA \& Perwad F 2012 Chronic inhibition of ERK1/2 signaling improves disordered bone and mineral metabolism in hypophosphatemic (Hyp) mice. Endocrinology 153 1806-1816. (doi:10.1210/en.2011-1831)

Zhao Q, Shepherd EG, Manson ME, Nelin LD, Sorokin A \& Liu Y 2005 The role of mitogen-activated protein kinase phosphatase- 1 in the response of alveolar macrophages to lipopolysaccharide: attenuation of proinflammatory cytokine biosynthesis via feedback control of p38. Journal of Biological Chemistry 280 8101-8108. (doi:10.1074/jbc. M411760200)

Received in final form 26 November 2012

Accepted 29 November 2012

Accepted Preprint published online 29 November 2012
(C) 2013 Society for Endocrinology Printed in Great Britain 